\title{
Shrinkage behaviour of flowable resin-composites related to conversion and filler-fraction
}

\author{
Kusai Baroudi ${ }^{a, b, *}$, Abeer M. Saleh ${ }^{b}$, Nick Silikas $^{b}$, David C. Watts ${ }^{b}$ \\ a Department of Paediatric Dentistry, University of Al-Baath, School of Dentistry, Hama, Syria \\ ${ }^{b}$ Biomaterials Research Group, The University of Manchester, School of Dentistry, Manchester, UK
}

\section{A R T I C L E I N F O}

Article history:

Received 5 March 2007

Received in revised form

1 May 2007

Accepted 2 May 2007

Keywords:

Flowables

Resin-composites

Shrinkage-strain

Filler-fraction

Degree of conversion

\begin{abstract}
A B S T R A C T
Objectives: To evaluate the shrinkage-strain, degree of conversion (DC) and percent filler of a range of flowable resin-composites.

Methods: Several commercially available flowable resin-composites were selected. The bonded-disk technique was used to measure shrinkage-strain kinetics. Measurements were obtained continuously for $60 \mathrm{~min}$ by irradiation for $40 \mathrm{~s}$ at $750 \mathrm{~mW} / \mathrm{cm}^{2}$ at two initial temperatures of 23 and $37^{\circ} \mathrm{C}$. Three repetitions $(n=3)$ were made at each temperature per material. The DC was measured by FTIR spectroscopy immediately post-cure. The percent filler was determined by combustion of specimens for $1 \mathrm{~h}$ at $400{ }^{\circ} \mathrm{C}$.

Results: The final values of shrinkage-strain ranged from 2.61 to $6.25 \%$ at $23^{\circ} \mathrm{C}$ and from 3.88 to $6.56 \%$ at $37^{\circ} \mathrm{C}$. Statistically significant differences $(p<0.05)$ were found in shrinkagestrain between the flowable resin-composites at both temperatures 23 and $37^{\circ} \mathrm{C}$. Significantly higher values were obtained at $37^{\circ} \mathrm{C}(p<0.05)$. A strong inverse correlation was found between the percent filler and the shrinkage-strain at 37 and $23^{\circ} \mathrm{C}\left(r^{2}=0.94\right.$ and 0.87 , respectively). No correlation was found between shrinkage-strain and DC $(p>0.05)$.

Conclusions: Flowable resin-composites vary widely in shrinkage-strain magnitude and the inverse relationship between filler percent and shrinkage-strain is explained by the corresponding decrease in volume fraction of monomers present to undergo polymerisation.
\end{abstract}

(C) 2007 Elsevier Ltd. All rights reserved.

\section{Introduction}

Restorative dentistry is experiencing a dynamic transition towards adhesive dentistry. A class of resin-composite systems, known as "flowable" composites, has become an integral part of the restorative process since they were first introduced in mid 1990's. These restorative materials were developed in response to requests for easy handling properties. ${ }^{1}$ They are characterized by either less filler loading or a greater proportion of diluent monomers in their composite formulation. They are designed to be less viscous, and so offer better adaptation to the internal cavity wall, easier insertion and greater elasticity than more highly viscous products. ${ }^{2}$
Flowability is regarded as a desirable handling property which allows the material to be injected through small gauge dispensers, thus simplifying the placement procedure and amplifying the possible range of clinical applications. ${ }^{3}$

Clinical applications of flowable materials have been critically reviewed by Bayne et al., ${ }^{4}$ who examined their usefulness besides flow, after a preliminary screening of physical properties. The authors suggested that, since flowability seemed to be achieved mainly by lowering the filler concentration, the first generation flowable composites may shrink considerably more than current non-flowable composites. For the same reason, these resins can be expected to be less rigid than the conventional hybrids.

\footnotetext{
* Corresponding author at: The University of Manchester, School of Dentistry, Higher Cambridge Street, M15 6HR, Manchester, UK.

E-mail address: d_kusai@yahoo.co.uk (K. Baroudi). 0300-5712/\$ - see front matter (C) 2007 Elsevier Ltd. All rights reserved.
} doi:10.1016/j.jdent.2007.05.001 
The properties of resin-composites depend primarily on their material composition. Correlations between filler content and mechanical properties are established for modulus of elasticity; the higher the filler content, the higher the modulus and the greater the resistance to deformation. Conversely, the lower the filler content, the greater the expected polymerisation shrinkage and lower the ability to resist deformation. ${ }^{5}$

Dimensional stability of dental resin-composites is essential to the longevity and function of the restoration. Dental composites consisting of dimethacrylate resins filled with inorganic filler particles undergo volumetric shrinkage when cured. ${ }^{6}$ This shrinkage results in corresponding stresses which may cause mechanical failure at the composite/tooth interface, de-bonding, microleakage and secondary caries in addition to enamel fractures. ${ }^{7,8}$

Significant differences in the polymerisation shrinkage exist among commercially available composite materials, depending on the resin formulation. ${ }^{9}$ The stress magnitude is dependent on C-factor, the ratio of bonded to free surfaces involved, ${ }^{10-12}$ on the material properties of the resin composite ${ }^{10,13,14}$ and on the amount of compliance of the substrate materials. ${ }^{15,16}$ Moreover, the kinetics of polymerization and network formation is dependent upon the wavelength, irradiation and duration of the initiating light, and especially upon the ambient and internal temperature levels produced during polymerization. ${ }^{17}$

Adequate polymerization is crucial in obtaining optimal physical properties and clinical performance of resin-composites. ${ }^{18}$ Ideally, a dental restorative resin might have all of its monomer converted to polymer during the polymerisation reaction. However, dimethacrylate monomers exhibit considerable residual $\mathrm{C}=\mathrm{C}$ bonds in the final product, with degree of conversion ranging from 55 to $75 \%$ under conventional irradiation conditions. ${ }^{19}$ The final degree of conversion depends on the chemical structure of the methacrylate monomer and the polymerization conditions, such as temperature and light intensity. ${ }^{20}$

However, the behaviour of flowable composites varies greatly, amongst the wide range of products now available, with a wide range of apparent viscosity. ${ }^{21}$

The aim of this study was to determine the shrinkage-strain of a range of commercially available flowable resin-composites in relation to the filler-fraction and the DC of these materials. The specific objectives were to measure: (i) shrinkage-strain at 23 and $37^{\circ} \mathrm{C}$, (ii) DC at $23^{\circ} \mathrm{C}$ and (iii) filler percentage by weight.

The null hypotheses were (1) the shrinkage-strain values will not be dependent on the filler-fraction of the material and (2) there is no correlation between shrinkage-strain values and the DC of the flowable composite materials.

\section{Materials and methods}

Seven commercially available flowable resin-composites were selected for this study (Table 1).

The bonded-disk technique was used to measure polymerization shrinkage-strain kinetics. This apparatus was developed by Watts and Cash ${ }^{22,23}$ with further modification by these authors to allow resin specimens to be environmentally heated to maintain a steady temperature throughout each test cycle, so that resin cure kinetics at different temperature could be determined. A disk-shaped specimen $(7 \mathrm{~mm} \times 1.5 \mathrm{~mm})$ was placed at the centre of a square crosssection circular brass ring acting as a spacer of internal diameter $16 \mathrm{~mm}$ and height $1.0 \mathrm{~mm}$. This ring was adhesively bonded onto a rigid glass plate, $74 \mathrm{~mm} \times 25 \mathrm{~mm} \times 3 \mathrm{~mm}$. The top edge of the ring and disc specimen were covered by a flexible $22 \mathrm{~mm}$ square cover-slip, thickness $0.1 \mathrm{~mm}$ (type 0 , Chance-Propper Ltd., Warley, UK). The tip of a dental curing light was positioned underneath and in close proximity of the glass plate, so that light-cure could be achieved by irradiating from below, through the glass.

A LVDT (linear variable displacement transducer) measuring system was positioned centrally onto the cover slip. Following thermal and mechanical equilibration, measurement runs were made by irradiation for $40 \mathrm{~s}$ at $750 \mathrm{~mW} / \mathrm{cm}^{2}$ at either 23 or $37^{\circ} \mathrm{C}$. Measurements were for $60 \mathrm{~min}$ from photoinitiation ( $n=3$ per material at each temperature).

The DC of the investigated flowable composites was measured by FTIR spectroscopy. A small amount of each material was placed between two translucent polyethylene strips which were compressed hard between two plastic blocks to produce a very thin film $(40-70 \mu \mathrm{m})$ of the material. Each material was then polymerised $(n=3)$, by irradiation at $23^{\circ} \mathrm{C}$. FTIR spectra of the thin films of uncured and cured material were recorded in transmission, on an FTIR spectrometer (Avatar 360, Nicolet Analytical Instruments, UK) operating under the following conditions: $2000-550 \mathrm{~cm}^{-1}$ wavelength; $4 \mathrm{~cm}^{-1}$ resolution; 16 scans co-addition. The DC was measured $10 \mathrm{~min}$ after curing and calculated using the ratios of two peaks $(\mathrm{C}=\mathrm{C}$ stretch of $1638 \mathrm{~cm}^{-1}$ analytical frequency and $C=C$ stretch at $1608 \mathrm{~cm}^{-1}$ reference frequency). The peak intensities as ratios of the uncured and cured material were calculated, and the DC was expressed in percentage relative to the uncured state.

The percent filler for each flowable composite was determined by combustion of the test specimens for $1 \mathrm{~h}$ at $400{ }^{\circ} \mathrm{C}$. Before and after combustion, the weights of the specimens were measured with a precision balance (E400D, Ohaus, Pine Brook, USA, accuracy $=0.1 \mathrm{mg}$ ).

Table 1 - Flowable composites: codes and sources

\begin{tabular}{lccc} 
Flowable composites & Code & Batch number & Manufacturer \\
\hline Revolution Formula 2 & RF & $3-1190$ & Kerr, Avenue Orange, USA \\
X-Flow & XF & 0404000035 & Dentsply York, USA \\
Admira Flow & AF & 440530 & Voco, Cuxhaven, Germany \\
Filtek Flow & FF & 3EP & 3M ESPE, Seefeld, Germany \\
Tetric Flow & TF & F47540 & Ivoclar Vivadent, Schaan, Liechtenstein \\
Grandio Flow & GF & 361443 & Voco, Cuxhaven, Germany \\
Point 4 Flowable & PF & 305A23 & Kerr, Avenue Orange, USA \\
\hline
\end{tabular}




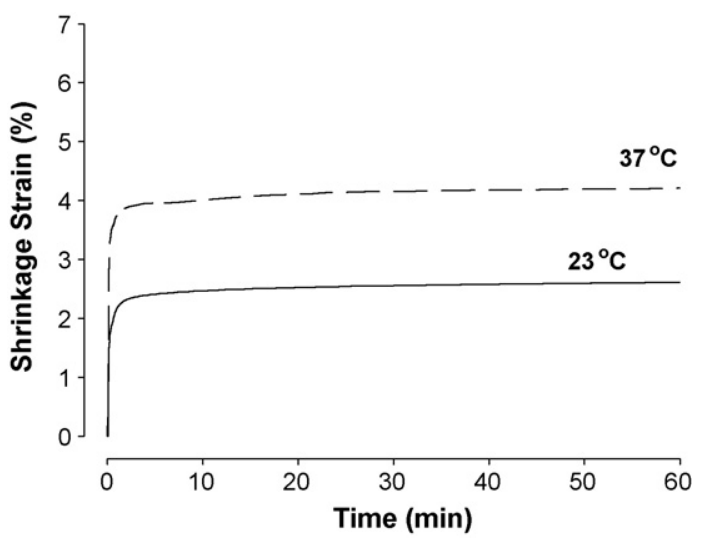

Fig. 1 - Time-dependence of shrinkage-strain for Point 4 Flowable at 23 and $37^{\circ} \mathrm{C}$.

All data were analyzed by one-way ANOVA SPSS (Version 11.5, SPSS Inc., USA) software package, with Student-Newman-Keuls post hoc test at the $\alpha=0.05$ level. A paired t-test was also used to differentiate statistically between the shrinkage-strain data at 23 and $37^{\circ} \mathrm{C}$.

\section{Results}

Mean final values and standard deviations of polymerisation shrinkage-strain are presented in Table 2 . These ranged from 2.61 to $6.25 \%$ at $23{ }^{\circ} \mathrm{C}$ and from 3.88 to 6.56 at $37^{\circ} \mathrm{C}$. Figs. 1 and 2 show the shrinkage-strain kinetics of Point 4 Flowable and XFlow, respectively, at both temperatures. Statistically significant differences $(p<0.05)$, were found in final shrinkagestrain between the flowable composites at both temperatures. Higher shrinkage-strain values for all materials were obtained at $37^{\circ} \mathrm{C}$. The Student-Newman-Keuls post hoc test applied to each material showed that Point 4 Flowable, Grandio Flow and Tetric Flow had lower shrinkage-strains than the other flowable composites with statistically significant differences.

The filler percentages of the flowable composites determined by combustion ranged from $54.5 \mathrm{wt}$ \% for Revolution Formula 2 to $71.3 \mathrm{wt}$ \% for Point 4 Flowable (Table 2). The highest filler percent flowable composites resulted in the lowest shrinkage-strains. A correlation was found between the percent filler and the polymerisation shrinkage-strain for

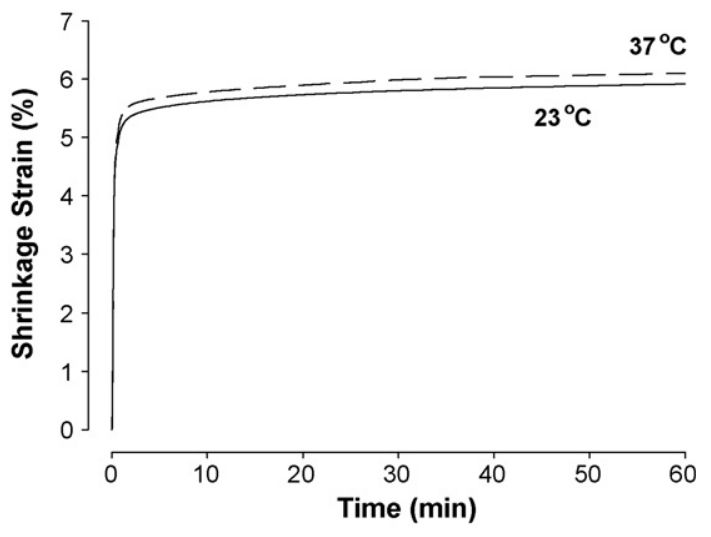

Fig. 2 - Time-dependence of shrinkage-strain for X-Flow at 23 and $37^{\circ} \mathrm{C}$.

both temperatures $\left(r^{2}=0.94\right)$ and $\left(r^{2}=0.87\right)$ for 37 and $23^{\circ} \mathrm{C}$, respectively (Fig. 3).

No correlation was found between shrinkage-strain and the DC of the flowable composites $(p>0.05)$. A statistically significant difference in $\mathrm{DC}$ at $23^{\circ} \mathrm{C}$ was found between the composites $(p<0.05)$ with DC ranging from $67.68 \%$ for Point 4 Flowable to $60.49 \%$ for Filtek Flow (Fig. 4).

\section{Discussion}

A range of new flowable resin-composites of different composition was used in this study. Measurements of shrinkage-strain, at two temperatures, together with DC and filler percentage of these flowable composites were achieved using established methods.

The final shrinkage-strain values, ranging from 2.61 to $6.25 \%$ at $23{ }^{\circ} \mathrm{C}$, are in broad agreement with previous results. ${ }^{3,4,24,25}$ Flowable composites exhibit generally higher shrinkage-strains than conventional composites, ${ }^{3}$ as expected from their lower filler loading. Point 4 Flowable demonstrated the lowest shrinkage-strain and Revolution Formula 2 showed the highest shrinkage value. This conforms with the idea that high filler loading reduces shrinkage-strain and can explain the range of values between the flowable resin-composites, together with the strong correlation between the shrinkagestrain and the filler content (Fig. 3). At high filler loadings the

Table 2 - Final mean percentage shrinkage-strains of flowable resin-composites after 60 min, irradiated at 23 and $37{ }^{\circ} \mathrm{C}$

\begin{tabular}{|c|c|c|c|c|}
\hline $\begin{array}{l}\text { Flowable } \\
\text { composites }\end{array}$ & $\begin{array}{l}\text { Percent filler (wt.\%) } \\
\text { by manufacturers }\end{array}$ & $\begin{array}{l}\text { Percent filler (wt.\%) } \\
\text { by combustion }\end{array}$ & $\begin{array}{l}\text { Mean strain (\%) } \\
\text { at } 23^{\circ} \mathrm{C} \text { (S.D.) }\end{array}$ & $\begin{array}{l}\text { Mean strain (\%) } \\
\text { at } 37^{\circ} \mathrm{C} \text { (S.D.) }\end{array}$ \\
\hline $\mathrm{RF}$ & 60.0 & $54.5(0.97)$ & $6.25(0.53)$ & $6.56(0.29)$ \\
\hline XF & 60.0 & $60.6(0.56)$ & $5.92(0.21)$ & $6.10(0.37)$ \\
\hline $\mathrm{AF}$ & 64.0 & $63.7(0.78)$ & $5.52(0.15)$ & $5.70(0.06)$ \\
\hline $\mathrm{FF}$ & 68.0 & $65.7(0.86)$ & $4.62(0.52)$ & $4.93(0.44)$ \\
\hline TF & 68.1 & $67.5(0.32)$ & $4.13(0.13)$ & $4.69(0.27)$ \\
\hline GF & 80.2 & $70.8(0.70)$ & $3.57(0.17)$ & $3.88(0.26)$ \\
\hline PF & 70.0 & $71.3(0.57)$ & $2.61(0.65)$ & $4.21(0.42)$ \\
\hline
\end{tabular}

Percent filler of these resin-composites obtained by combustion and manufacturers. 


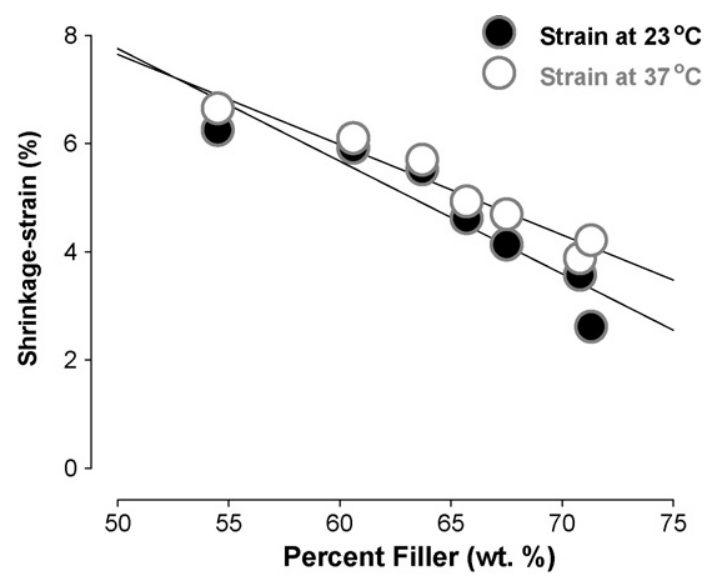

Fig. 3 - Correlation between mean shrinkage-strain maxima after $60 \mathrm{~min}$ at 23 and $37^{\circ} \mathrm{C}$ and percent filler for the flowable resin-composites.

plot tended to become curvilinear, which could by extrapolation express the possibility of zero shrinkage. Thus, the first hypothesis was rejected.

The higher shrinkage-strains of flowable resin-composites obviously relate to their resin content, and possibly also to the chemical nature of their resin and specific DC. ${ }^{26}$ Flowables have a high proportion of monomers in the formulation of the composite paste, particularly a large amount of a diluent monomer, commonly TEGDMA, added to a bulkier and structurally rigid base monomer, such as Bis-GMA or UDMA to reduce the viscosity. ${ }^{27}$ The number of polymerised double bonds increases with decreasing molecular weight of the monomers, such as TEGDMA. Therefore, the total shrinkage of the resin increases as TEGDMA percentage increases. ${ }^{28,29}$

When the temperature was increased to $37^{\circ} \mathrm{C}$, the shrinkage-strain also increased. The effect of the increased temperature on shrinkage-strain values could be due to an increase in the network conversion of resin monomer. Due to the enhanced thermal mobility of the reacting network leading to an enhanced network of $\mathrm{C}-\mathrm{C}$ bonds, the shrinkage-strain increases with temperature. ${ }^{23,30}$ When resin-composites are placed in dental cavities, the temperature will rise towards $37^{\circ} \mathrm{C}$ at a rate normally governed by their thermal

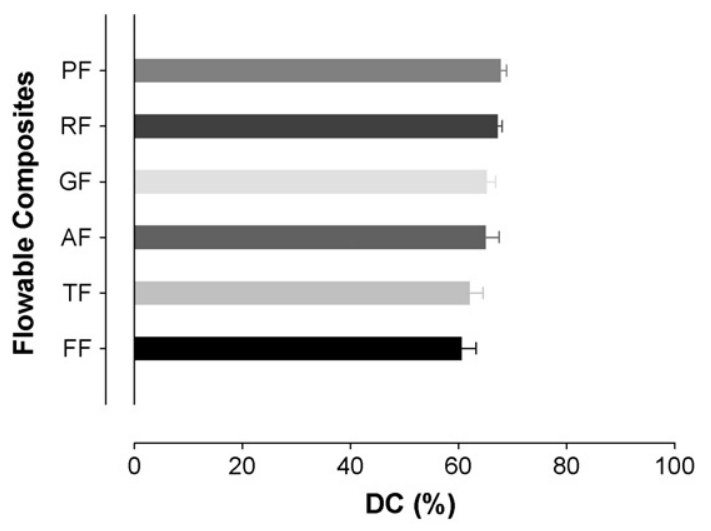

Fig. 4 - DC (\%) at $23^{\circ} \mathrm{C}$ for the flowable resin-composites. diffusivity. Practically, it usually takes 1-2 min to place a resin composite in a dental cavity prior to irradiation. Hence, the materials may be irradiated clinically at temperatures anywhere between 23 and $37^{\circ} \mathrm{C}$. If the resin-composites were prerefrigerated, the temperature could stay close to $23^{\circ} \mathrm{C}$.

In the present study, the percent filler content of flowable composite was investigated by combustion technique. This technique is based on elimination of the organic fraction of a resin-composite by heating at a constant temperature. Different temperatures have been previously used. Kim et $\mathrm{al}^{31}$ ashed the composites at $600^{\circ} \mathrm{C}$ during $30 \mathrm{~min}$, while Chung and Greener ${ }^{32}$ used $700{ }^{\circ} \mathrm{C}$ to ash the materials. In this study, they were ashed for $60 \mathrm{~min}$ at $400{ }^{\circ} \mathrm{C}$ and the numbers obtained were similar to those provided by the manufacturers except for Grandio Flow and Revolution Formula 2. A reasonable explanation could be that the manufacturers' treat the filler-matrix interface according to their own original methods and used different ways of calculation of the percentage of fillers. Some manufacturers might calculate the percentage of fillers before the silanization process while others might include the percentage of silane coating in their calculations. For Grandio Flow, the nature of nanofillers might have contributed in them escaping during ashing with the organic fraction.

The DC values were obtained by a thin film transmission techniques. There are several methods to determine DC. Fourier transformation infrared spectroscopy (FTIR) has been proven to be a powerful technique and has been widely used as a reliable method. ${ }^{20,33,34}$ Even though there are several factors affecting the DC of resin-composites, the differences in the DC values observed here could be related to the differences in the resin matrix composition of these materials. DC increases when TEGDMA increases, up to a certain point. Flowable composite materials often have a greater proportion of TEGDMA which does not usually reach that critical TEGDMA concentration where primary cyclisation may be prevalent, due to high chain mobility, which may limit conversion. Generally, the higher the conversion in resincomposites, the higher the shrinkage. ${ }^{19}$ However, in the present work, no correlation was found between the DC and shrinkage-strain of flowable resin-composites. The second null hypothesis was rejected. It appears that the influence of filler loading on shrinkage-strain is the over-riding factor. Evidently, the correlation between DC and shrinkage-strain of flowable resin-composites is material-dependent and cannot be generalised to all flowable resin-composites. Moreover, shrinkage-strain and DC were tested, due to the nature of the experiments, using different sample thicknesses which may affect the correlation between shrinkagestrain and DC. The correlation of DC and shrinkage-strain might also be affected by particle size and shape and resultant elastic modulus.

A significant difference in shrinkage-strain between 37 and $23^{\circ} \mathrm{C}$ was noticed with Point 4 Flowable compared with Filtek Flow. This could be attributed to the differences in composition of these materials. In addition to Bis-GMA and TEGDMA Filtek Flow contains a dimethacrylate polymer that modifies the rheology of the material and may influence the effect of temperature on the network conversion and thus the shrinkage-strain. 


\section{Conclusion}

The polymerisation shrinkage-strain of flowable composites should be taken into consideration in combination with their filler-fraction, which highly influences their shrinkage behaviour. Lower filler loading flowables, such as Revolution Formula 2 and X-Flow, are more likely to be highly fluid materials. Even though these materials exhibited substantial polymerisation shrinkage, they might be successfully used in micro-conservative occlusal cavities, as the consequences of polymerisation shrinkage would be low because of the limited volume of the material used.

\section{R E F E R E N C E S}

1. Lee $\mathrm{JH}$, Um CM, Lee IB. Rheological properties of resin composites according to variations in monomer and filler composition. Dental Materials 2006;22:515-26.

2. Payne JH. The marginal seal of class II restorations: flowable composite resin compared to injectable glass ionomer. Journal of Clinical Pediatric Dentistry 1999;23:123-30.

3. Labella R, Lambrechts P, Meerbeek BV, Vanherle G. Polymerization shrinkage and elasticity of flowable composites and filled adhesives. Dental Materials 1999;15:128-37.

4. Bayne SC, Thompson JY, Swift EJJ, Stamatiades P, Wilkerson M. A characterization of first-generation flowable composites. Journal of American Dental Association 1998;129:567-77.

5. Braem M, Finger W, Doren VEV, Lambrechts P, Vanherle G. Mechanical properties and filler fraction of dental composites. Dental Materials 1989;5:346-8.

6. Venhoven BAM, de Gee AJ, Davidson CL. Polymerization contraction and conversion of light curing Bis-GMA-based methacrylate resins. Biomaterials 1993;14:875-971.

7. Davidson CL, Feilzer AJ. Polymerization shrinkage and polymerization shrinkage stress in polymer-based restoratives. Journal of Dental Research 1997;25:435-40.

8. Millar BJ, Nicholson JW. Effect of curing with a plasma light on the properties of polymerizable dental restorative materials. Journal of Oral Rehabilitation 2001;28:549-52.

9. Feilzer AJ, de Gee AJ, Davidson CL. Curing contraction of composites and glass-ionomer cements. Journal of Prosthetic Dentistry 1988;59:297-300.

10. Bowen RL. Adhesive bonding of various materials toward tooth tissues: VI. Forces developing in direct filling materials during hardening. Journal of American Dental Association 1967;74:439-45.

11. Davidson CL, de Gee AJ. Relaxation of polymerization contraction stresses by flow in dental composites. Journal of Dental Research 1984;63:146-8.

12. Feilzer AJ, de Gee AJ, Davidson CL. Setting stress in composite resin relation to configuration of the restoratives. Journal of Dental Research 1987;66:1636-9.

13. Hegdahl T, Gjerdet NR. Contraction stresses of composite resin filling materials. Acta Odontologica Scandinavica 1977;35:191-5.

14. Feilzer AJ, de Gee AJ, Davidson CL. Quantitative determination of stress reduction by flow in composite restorations. Dental Materials 1990;6:167-71.
15. Kemp-Scholte CM, Davidson CL. Marginal sealing of curing contraction gaps in class $\mathrm{V}$ composite resin restorations. Journal of Dental Research 1988;67:841-5.

16. Alster D, Feilzer AJ, de Gee AJ, Davidson CL. Polymerization contraction stress in thin resin composite layers as a function of layer thickness. Dental Materials 1998;13: 146-50.

17. Watts DC, Marouf AS. Optimal specimen geometry in bonded-disk shrinkage-strain measurements on light-cured biomaterials. Dental Materials 2000;16:447-51.

18. Chung $\mathrm{KH}$. The relation between composition and properties of posterior resin composites. Journal of Dental Research 1989;69:852-6.

19. Silikas N, Eliades G, Watts DC. Light intensity effects on resin-composite degree of conversion and shrinkage strain. Dental Materials 2000;16:292-6.

20. Sideridou I, Tserki V, Papanastasiou G. Effect of chemical structure on degree of conversion in light-cured dimethacrylate-based dental resins. Biomaterials 2002;23:1819-29.

21. Attar N, Tam LE, McComb D. Flow, strength, stiffness and radiopacity of flowable resin composites. Journal of Canadian Dental Association 2003;69:516-21.

22. Watts DC, Cash AJ. Determination of polymerization shrinkage kinetics in visible-light-cured materials: methods development. Dental Materials 1991;7:281-7.

23. Watts DC, al Hindi A. Intrinsic 'soft-start' polymerisation shrinkage-kinetics in an acrylate-based resin-composite. Dental Materials 1999;15:39-45.

24. Kleverlaan CJ, Feilzer AJ. Polymerization shrinkage and contraction stress of dental resin composites. Dental Materials 2005;21:1150-7.

25. Stavridakis MM, Dietschi D, Krejci I. Polymerization shrinkage of flowable resin-based restorative materials. Operative Dentistry 2005;30:118-28.

26. Tezvergil A, Lassila LV, Vallittu PK. The effect of fiber orientation on the polymerization shrinkage strain of fiber-reinforced composites. Dental Materials 2006;22:610-6.

27. Stansbury JW, Trujillo-Lemon M, Lu H, Ding X, Lin Y, Ge J. Conversion-dependent shrinkage stress and strain in dental resins and composites. Dental Materials 2005;21:56-67.

28. Alvarez-Gayosso C, Barcelo-Santana F, Guerrero-Ibarra J, Saez-Espinola G, Canseco-Martinez MA. Calculation of contraction rates due to shrinkage in light-cured composites. Dental Materials 2004;20:228-35.

29. Atai M, Watts DC, Atai Z. Shrinkage strain-rates of dental resin-monomer and composite systems. Biomaterials 2005;26:5015-20.

30. Watts DC. Reaction kinetics and mechanics in photopolymerised networks. Dental Materials 2005;1:27-35.

31. Kim KH, Ong JL, Okuno O. The effect of filler loading and morphology of the mechanical properties of contemporary composites. Journal of Prosthetic Dentistry 2002;6:642-9.

32. Chung KH, Greener EH. Correlation between degree of conversion, filler concentration and mechanical properties of posterior composite resins. Journal of Oral Rehabilitation 1990;17:487-94.

33. Imazato S, McCabe JF, Tarumi H, Ehara A, Ebisu S. Degree of conversion of composites measured by DTA and FTIR. Dental Materials 2001;17:178-83.

34. Imazato S, Tarumi H, Kato S, Ebi N, Ehara A, Ebisu S. Water sorption, degree of conversion, and hydrophobicity of resins containing Bis-GMA and TEGDMA. Journal of Dental Materials 1999;18:124-32. 